\title{
Methylphenidate-induced conditioned taste aversions: An index of toxicity
}

\author{
ANTHONY L. RILEY and DEBRA A. ZELLNER \\ The American University, Washington, D.C. 20016
}

\begin{abstract}
Following consumption of saccharin, groups of rats were injected with various doses of methylphenidate hydrochloride. Small aversions were found after one conditioning trial, with repeated saccharin-methlyphenidate pairings resulting in continued decrements in consumption. The strength of the aversion as well as the amount of individual variability were doserelated, with weaker aversions and greater individual variability occurring at the smaller dose $(15 \mathrm{mg} / \mathrm{kg})$. Although aversions were quite pronounced at higher doses, individual variability, although small, was still evident. The similarities and differences between methylphenidate-induced aversions and aversions based on emetics were discussed, along with the implications of these results as indices for methylphenidate-induced toxicity.
\end{abstract}

Recently, considerable interest has been devoted to finding effective, low-risk substitutes in the treatment of a number of clinical disorders (Hammond \& Joyce, 1975; Julien, 1976). For example, although amphetamine is quite effective in calming hyperkinetic children, the likelihood of acute and chronic toxicity and the possibility of dependence make amphetamine a substantial risk in treatment. A number of amphetamine-like substitutes have been promoted which appear equally effective in clinical treatment, but which lack the demonstrated toxic side effects and abuse potential of amphetamine. One specific substitute is methylphenidate hydrochloride.

As suggested, methylphenidate, although chemically very similar to amphetamine (Julien, 1976), produces fewer and milder toxic side effects. For example, Meier, Gross, and Tripod (1954) have reported that in dogs, methylphenidate "especially on peroral administration has a relatively low toxicity." Similarly, in a single case study, Pollack (1964) reported no toxic side effects of methylphenidate even with extremely high doses $(1,200 \mathrm{mg} /$ day $)$.

Although methylphenidate is typically assumed to be relatively free of toxic effects (Natenshon, 1956; Oettinger \& Majovski, 1976), a number of problems prevent such a general conclusion. The basis for conclusions regarding methylphenidate toxicity are often based on single-subject case history analysis (Pollack, 1964). Such an analysis often fails to consider possible individual variability in response to methylphenidate and, because of the clinical setting, often does not lend itself to control procedures. Such factors as drug histories, route of administration,

Requests for reprints should be sent to Anthony L. Riley, Department of Psychology, The American University, Washington, D.C. 20016. and dosimetry (Chernoff, 1962; Lucas \& Weiss, 1971; Natenshon, 1956; Palatucci, 1974) are compounded to such an extent that general conclusions regarding toxicity can only be cautiously made.

These problems, in addition to a number of reports implicating methylphenidate toxicity (Conners \& Eisenberg, 1963; Meier et al., 1954; Palatucci, 1974) suggest that a controlled and sensitive index of toxicity be examined for methylphenidate. One such design which has received some attention in assessing drug toxicity or stress is conditioned food aversions (Garcia \& Ervin, 1968; Revusky \& Garcia, 1970). Food aversion is a phenomenon whereby animals avoid consumption of a particular substance previously paired with poison (Chitty, 1954). Although initially demonstrated in rats poisoned by Xirradiation (Garcia, Kimeldorf, \& Koelling, 1955), food aversions have now been established by a large number of drug classes; minor tranquilizers (chlordiazepoxide); narcotics (morphine) ; barbituates (phenobarbital); and stimulants (amphetamine) (Riley \& Clarke, 1977). In relation to the stimulants, for example, animals injected with d-amphetamine, 1amphetimine, methamphetamine, d-fenfluramine, and $\mathrm{l}$-fenfluramine following consumption of a particular solution show strong and dose-related conditioned aversions.

While food aversions are often presented in the context of toxicity, it is important to note that aversions may be only an indirect and incomplete index of toxicity (Ionescu \& Burešová, 1977; Nachman \& Hartley, 1975). A number of drugs which are severely debilitating, e.g., cyanide, strychnine, and warfarin, are weak or totally ineffective in producing food aversions. Such failures may be a function of a critical duration of drug action necessary for the efficacy of an unconditioned stimulus in establishing food aversions, a duration of action possibly out 
of the range of the aforementioned failures (Coussens, 1974; Goudie, Dickens, \& Thornton, Note 1). While these exceptions do exist, the avoidance of a previously poisoned solution is typically assumed to be a result of the learned association between the taste of the solution and the toxic, i.e., illness-inducing (Garcia \& Ervin, 1968), stressing (Riley, Jacobs, \& LoLordo, 1976), or physiologically novel (Gamzu, 1977) aspects of the administered drug.

Because of the general paucity of data on methylphenidate toxicity, the present report examined the effectiveness of methylphenidate to condition food aversions, an index of toxicity. In addition to this general assessment, dose-response and repeated exposure effects were also examined within the same paradigm.

\section{METHOD}

\section{Subjects}

The subjects were 21 experimentally naive female rats of LongEvans descent, approximately $90-120$ days of age at the beginning of the experiment. They were maintained on ad lib access to food but were water-deprived throughout the experiment. All animals were maintained on a 12-h-light/12-h-dark cycle for the duration of the experiment.

\section{Apparatus}

The rats were housed in individual wire-mesh cages. In the front of each cage were openings into which graduated Nalgene tubes were placed for presentation of water or sodium saccharin ( $1 \mathrm{~g} /$ liter).

\section{Procedure}

The subjects were given 20 -min access to water once a day for 15 consecutive days, at which point all rats approached and drank from the tube within $2 \mathrm{sec}$ of its presentation. Then different treatments were administered to four groups of subjects. On Day 16 , Group $15(\mathrm{n}=5)$ was given 20 -min access to saccharin followed immediately by an intraperitoneal (IP) injection of $15 \mathrm{mg} / \mathrm{kg}$ of methylphenidate hydrochloride (Ritalin: CibaGeigy $\left.{ }^{1}\right)$. Similarly, Group $30(n=6)$ and Group $45(n=5)$ were given 20-min access to saccharin, followed immediately by an IP injection of 30 and $45 \mathrm{mg} / \mathrm{kg}$ of methylphenidate, respectively. Finally, Group $C(n=5)$ was given 20 -min access to saccharin. followed immediately by an IP injection of sterile water.

Following this treatment, all subjects were given 20-min access to water for 3 consecutive recovery days. On the day following the last recovery session, all subjects were given 20 -min access to saccharin in a one-bottle test of the aversion to saccharin. Immediately following this test, Groups 15,30 , and 45 were given an IP injection of 15,30 , and $45 \mathrm{mg} / \mathrm{kg}$ of methylphenidate, respectively. Again, Group $\mathrm{C}$ received an injection of sterile water following consumption of saccharin. Three water recovery days again were given following this treatement.

This cycle of conditioning trial followed by 3 recovery days was repeated until all subjects had received six complete cycles. Following the last cycle, a final one-bottle test of the aversion to saccharin was given.

\section{RESULTS}

All determinations of statistical significance were made at $\mathrm{p}<.05$, two-tailed.
Over the 15 water-adaptation days, rats in all groups gradually increased consumption of water, drinking approximately $13 \mathrm{ml} /$ day over the final 3 days of water adaptation. There were no significant differences in water consumption among groups at this point. When saccharin replaced water on Day 16 , there was a significant decrease in consumption below the water baseline (Day 15) for Group 15 [t(5) = 3.35]. There were no significant changes from baseline consumption for any other group. There were no significant differences in saccharin consumption among any group on this day, with each group drinking approximately $12 \mathrm{ml}$ (see Figure 1, Conditioning Trial 1).

On the first one-bottle test of the aversion to saccharin (Day 20, Conditioning Trial 2), Group 30 significantly decreased consumption of saccharin below its saccharin baseline (Day 16) $[\mathrm{t}(5)=3.32]$. There were no significant changes in consumption for the remaining groups. On this first aversion test, Groups 30 and 45 drank significantly less saccharin than sterile water-injected Group $C[t(9)=5.75$ and $t(8)=2.68$ for Groups 30 and 45 , respectively]. Group 30 also drank significantly less saccharin than Group $15[t(9)=3.20]$. No other comparisons were significant (see Figure 1, Day 20).

Over repeated conditioning trials, Groups 30 and 45 continued to decrease consumption of saccharin below their initial saccharin baselines $[F(6,30)=$ 36.26 and $F(6,24)=78.41$ for Groups 30 and 45 , respectively]. There were no significant changes in saccharin consumption over trials for Groups 15 and $\mathrm{C}$.

On the final aversion test, all groups injected with methylphenidate drank significantly less saccharin than Group $C$, the sterile water-injected subjects $[F(3,17)=10.88]$. There were, however, no significant differences in consumption of saccharin among methylphenidate-injected subjects.

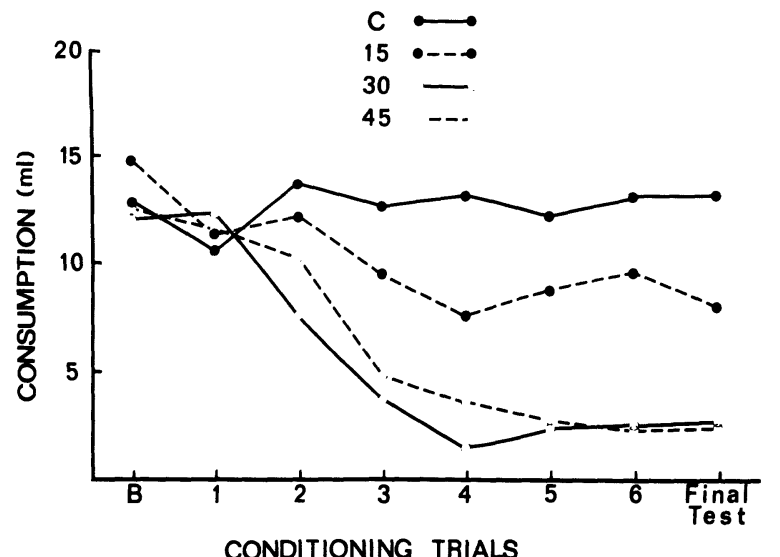

Figure 1. Mean consumption of saccharin for Groups $C, 15$, 30 , and 45 on the final day of water baseline (B), over repeated conditioning trials and on the final aversion test. 
There was considerable variability in the effect of methylphenidate on saccharin consumption for individual subjects in each group. This variability is most pronounced in Group 15; however, it is still evident in Groups 30 and 45. For example, on the final aversion test, the standard deviations of saccharin consumption for Groups 15,30 , and 45 were $4.42,3.96$, and 3.28 , respectively. This variability is in marked contrast to the consistency in the amount consumed within Group C, standard deviation, 1.46 (see Figure 2, Final Test). Although there was considerable variability within each group, individual subjects were very consistent in the amount of saccharin consumed over repeated trials. For example, over the final three conditioning trials, the mean standard deviations for subjects in Groups $\mathrm{C}$, 15,30 , and 45 were $0.76,1.48,0.75$, and 0.39 , respectively (see Figure 2, Conditioning Trials 5 and 6, and Final Test).

\section{DISCUSSION}

As described above, methylphenidate is used as an effective, nontoxic substitute for amphetamine in the treatment of a number of clinical disorders (Knobel, 1962; Swonger \& Constantine, 1976; Yoss \& Daly, 1968). Although typically described as nontoxic at behaviorally effective dosages, when conditioned food aversions were used as an index of toxicity, methylphenidate was effective in conditioning an aversion to a previously accepted novel solution. Rats injected with methylphenidate following consumption of a novel saccharin solution rapidly acquired a marked aversion to that solution. In addition, the aversion appeared dose related, with rats injected with larger doses of methylphenidate acquiring the aversion more rapidly and with less variability.

The aversions established by methylphenidate were also as rapidly and completely acquired as aversions established by more toxic, clinically less-preferred stimulants, e.g., d,l,meth-amphetamine (Cappell \& LeBlanc, 1975; Goudie, Thornton, \& Wheatley, 1975). In fact, although not as complete, methylphenidate-induced aversions were quite similar in strength and rate of acquisition to those established by general emetics and toxins, e.g., cyclophosphamide (Elkins, 1974), lithium chloride (Riley et al., 1976), and radiation (Garcia et al., 1955).

Although similar to emetics in establishing aversions, there is at least one substantial difference between aversions induced by methylphenidate and the aforementioned drugs, i.e., individual variability. As described, rats injected with methylphenidate avoided consumption on subsequent exposures. A number of animals in each methylphenidate group, however, showed only a moderate decrease or no decrease in consumption following the saccharinmethylphenidate pairings. This variability is in marked contrast to the general consistency among

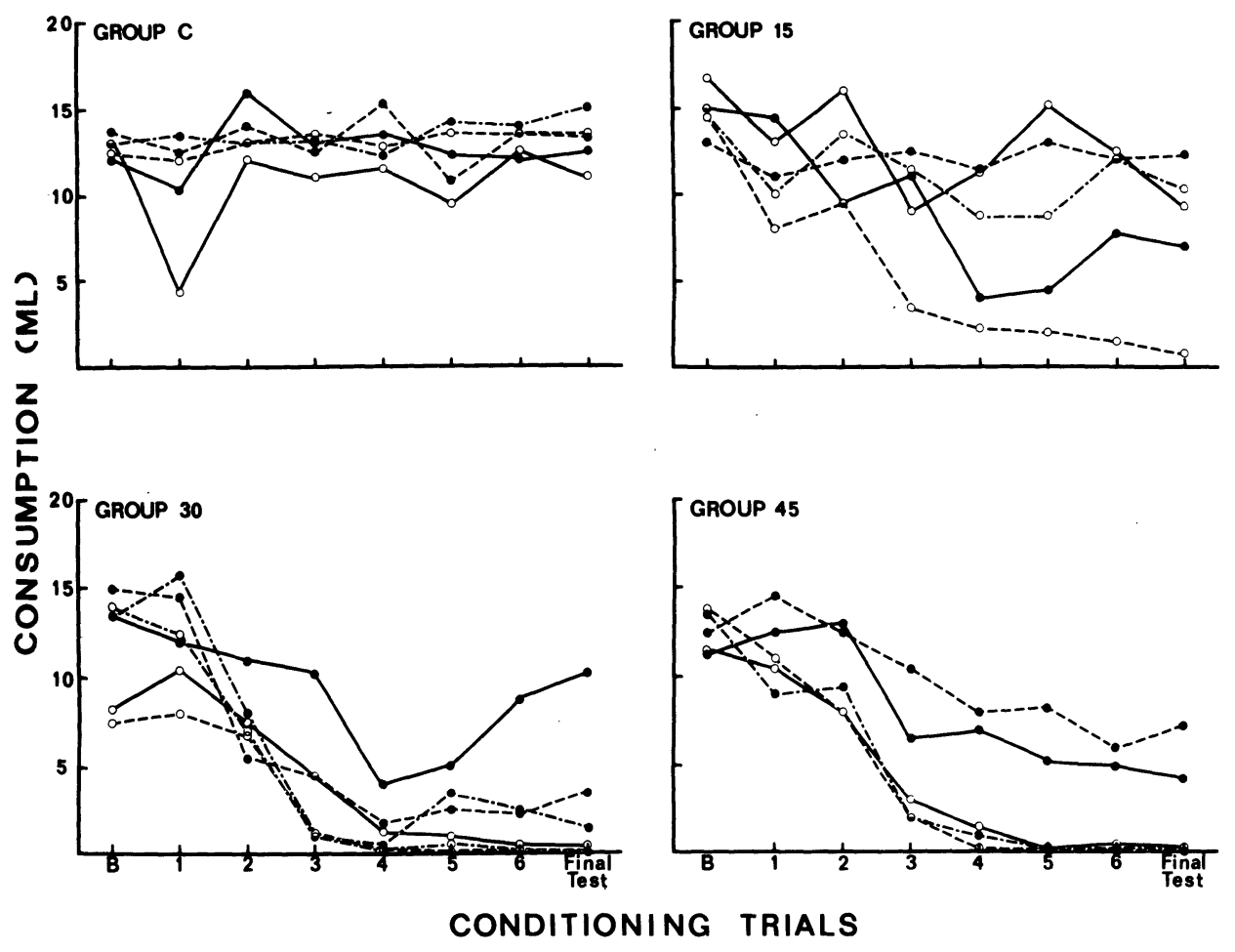

Figure 2. Consumption of saccharin for individual subjects in Groups $C, 15,30$, and 45 on the final day of water baseline $(B)$, over repeated conditioning trials and on the final aversion test. 
subjects of emetic-induced aversions, especially after repeated conditioning trials (Riley et al., 1976). These drug differences in individual variability could be a result of either quantitative or qualitative differences between methylphenidate and emetics.

For example, any differences between two drugs could reflect differences in the specific doses administered (Levine, 1973). In the present experiment, if the doses of methylphenidate had been substantially increased, it is possible that all subjects would have acquired a conditioned aversion. This explanation is supported by the fact that more individual variability was seen in Group 15 , subjects receiving the smallest dose of methylphenidate. The failure of several rats to acquire aversions at higher doses and after repeated trials appears to argue against this, although even this variability could reflect individual differences in the pharmacologic effect of the drug (Kalant, LeBlanc, \& Gibbons, 1971) and in the onset of tolerance (Riley \& Zellner, Note 2).

A second interpretation of the drug differences in individual variability is that there is something qualitatively different between methylphenidate and emetics such as lithium chloride. For example, similar to methylphenidate, aversions established by morphine sulfate are quite variable among subjects (Farber, Gorman, \& Reid, 1976; Riley, Jacobs, \& LoLordo, 1978). This individual variability is quite large even at high doses, e.g., 50 and $80 \mathrm{mg} / \mathrm{kg}$. One explanation of this variability with morphine might be the dual, paradoxical effects morphine produces in animals. For example, while morphine is effective in establishing food aversions, animals will self-administer the same dose in a positive reinforcement paradigm (White, Sklar, \& Amit, 1977; Wise, Yokel, \& deWit, 1976). These procedural positive and negative effects of morphine have been well documented (Cappell \& LeBlanc, 1977; Sklar \& Amit, 1977). If the acquisition of aversions is dependent or affected by the positive, reinforcing effects of the drug, and if these dual effects interact at all differently in individual subjects, individual variability in the strength of food aversions should be evident with any drug producing these dual, paradoxical effects. Although methylphenidate is reported to have no reinforcing effects and thereby low abuse potential, there are at least several reports demonstrating self-administration in dogs (Risner \& Jones, 1975), nonhuman primates (Brady \& Griffiths, 1976), and humans (Rioux, 1960).

Previous research and case reports have systematically concluded that methylphenidate is a clinically effective, nontoxic amphetamine substitute. It is clear from the present report, however, that similar to established toxins and stressors, methylphenidate is effective in establishing food aversions. While only a single index of toxicity, the present data do question the general conclusion of the low-risk, nontoxic nature of methylphenidate.

\section{REFERENCE NOTES}

1. Goudie, A. J., Dickens, D. W., \& Thornton, E. W. Cocaineinduced taste aversions in rats. Unpublished manuscript.

2. Riley, A. L., \& Zellner, D. A. Signalled and unsignalled preexposure to methylphenidate: The role of drug tolerance in the pre-exposure effect. Unpublished manuscript.

\section{REFERENCES}

BRADY, J. V., \& Griffiths, R. R. Behavioral procedures for evaluating the relative abuse potential of CNS drugs in primates. Federation Proceedings, 1976, 35, 2245-2253.

Cappell, H. D., \& LeBlanc, A. E. Conditioned aversion by amphetamine: Rates of acquisition and loss of the attenuating effects of prior exposure. Psychopharmacologia, 1975, 43, 157-162.

Cappell, H. D., \& LeBlanc, A. E. Gustatory avoidance conditioning by drugs of abuse: Relationships to general issues in research on drug dependence. In N. W. Milgram, L. Krames, \& T. M. Alloway (Eds.), Food aversion learning. New York: Plenum Press, 1977.

Chernoff, R. W., Wallen, M. H., \& Muller, O. F. Cardiac toxicity of methylphenidate: Report of two cases. New England Journal of Medicine, 1962, 266, 400-401.

ChItTY, D. (ED.). Control of rats and mice (Vol. 1). Oxford: Clarendon Press, 1954.

Conners, C. K., \& Eisenberg, L. The effects of methylphenidate on symptomatology and learning in disturbed children. American Journal of Psychiatry, 1963, 120, 458-464.

Coussens, W. R. Conditioned taste aversion: Route of drug administration. In J. M. Singh \& H. Lal (Eds.), Drug addiction: Neurobiology and influences on behavior (Vol. 3). Miami: Symposium Specialists, 1974.

ELKINS, R. L. Bait-shyness acquisition and resistance to extinction as functions of US exposure prior to conditioning. Physiological Psychology, 1974, 2, 341-343.

Farber, P. D., Gorman, J. E., \& ReId, L. D. Morphine injections in the taste aversion paradigm. Physiological Psychology, 1976, 4, 365-368.

GAMZU, E. The multifaceted nature of taste-aversion inducing agents: Is there a single common factor? In L. M. Barker, M. R. Best, \& M. Domjan (Eds.), Learning mechanisms in food selection. Waco, Tex: Baylor University Press, 1977.

GARCIA, J., \& ERVIN, F. R. Gustatory-visceral and telereceptorcutaneous conditioning: Adaptation in internal and external milieus. Communications in Behavioral Biology, 1968, 1, 389-415.

Garcia, J., Kimeldorf, D. J., \& Koelling, R. A. Conditioned aversion to saccharin resulting from exposure to gamma radiation. Science, 1955, 122, 157-158.

Goudie, A. J., Thornton, E. W., \& Wheatley, J. Attenuation by alpha-methyltyrosine of amphetamine induced conditioned taste aversion in rats. Psychopharmacologia, 1975, 45, 119-123.

Hammond, K. R., \& Joyce, C. R. B. Psychoactive drugs and social judgment: Theory and research. New York: Wiley, 1975.

IONESCU, E., \& BurEšová, O. Failure to elicit conditioned taste aversion by severe poisoning. Pharmacology, Biochemistry, and Behavior, 1977, 6, 251-254.

Julien, R. M. A primer of drug action. San Francisco: Freeman, 1976.

Kalant, J., LeBlanc, A. E., \& Gibbons, R. J. Tolerance to, and dependence on, some non-opiate psychotropic drugs. Pharmacological Review, 1971, 23, 135-191.

KNoBel, M. Psychopharmacology for the hyperkinetic child. Archives of General Psychiatry, 1962, 6. 198-202. 
LeVINe, R. Pharmacology: Drug actions and reactions. Boston: Little, Brown, 1973.

LuCAS, A. R., \& WeIss, M. Methylphenidate hallucinosis. Journal of the American Medical Association, 1971, 217, 1079-1081.

Meier, R., Gross, F., \& TrIPod, J. Ritaline, eine neuartige synthetische Verbindung mit spezifischer zentralerregender Wirkingskomponente. Klinischer Wochenschrift, 1954, 32, 445-450.

NaChMan, M., \& Hartley, P. L. Role of illness in producing learned taste aversions in rats: A comparison of several rodenticides. Journal of Comparative and Physiological Psychology, 1975, 89, 1010-1018.

Natenshon, A. L. Clinical evaluation of ritalin. Diseases of the Nervous System, 195ó, 17, 392-396.

Oettinger, L., JR., \& Majovskn, L. V. Methylphenidate: A review. Southern Medical Journal, 1976, 69, 161-163.

Palatucci, D. M. Iatrogenic dyskinesia: A unique reaction to parenteral methylphenidate. Journal of Nervous and Mental Disease, 1974, 159, 73-76.

Pollack, B. Report of an unusually large dosage of methylphenidate hydrochloride. American Journal of Psychiatry, 1964, 121, 189-190.

REVUSKY, S., \& GaRCIA, J. Learned associations over long delays. In G. H. Bower \& J. T. Spence (Eds.), Psychology of learning and motivation: Advances in research and theory (Vol. 4). New York: Academic Press, 1970.

Riley, A. L., \& Clarke, C. M. Conditioned taste aversions: A bibliography. In L. M. Barker, M. R. Best, \& M. Domjan (Eds.), Learning mechanisms in food selection. Waco, Tex: Baylor University Press, 1977.

Riley, A. L., JACoBs, W. J., \& LoLordo, V. M. Drug exposure and the acquisition and retention of a conditioned taste aversion. Journal of Comparative and Physiological Psychology, 1976, 90, 799-807.
RILEY, A. L., JACoBs, W. J., \& LoLoRdo, V. M. Morphineinduced taste aversions: A consideration of parameters. Physiological Psychology, 1978, 6, 96-100.

Rioux, B. Is Ritalin an addiction-producing drug? Diseases of the Nervous System, 1960, 21, 346-349.

RisNer, M. E., \& JonEs, B. E. Self-administration of CNS stimulants by dog. Psychopharmacologia, 1975, 43, 207-213.

SKLAR, L., \& AMIT, Z. Manipulations of catecholamine systems block the conditioned taste aversion induced by self-administered drugs. Neuropharmacology, 1977, 16, 649-655.

Swonger, A. K., \& Constantine, L. L. Drugs and therapy: A psychotherapist's handbook of psychotropic drugs. Boston: Little, Brown, 1976.

White, N., Sklar, L., \& Amit, Z. The reinforcing action of morphine and its paradoxical side effect. Psychopharmacology, 1977, 52, 63-66.

Wise, R. A., YoKel, R. A., \& DeWIT, H. Both positive reinforcement and conditioned aversion from amphetamine and from apomorphine in rats. Science, 1976, 191, 1273-1274.

Yoss, R. E., \& Daly, D. D. On the treatment of narcolepsy. Medical Clinics of North America, 1968, 52, 781-787.

\section{NOTE}

1. The authors would like to thank Ciba-Geigy for generously supplying the methylphenidate $\mathrm{HCl}$.

(Received for publication October 25, 1977; revision accepted April 4, 1978.) 